\title{
Colonization With Staphylococcus aureus Subtypes in Pediatric Patients With Atopic Dermatitis
}

\author{
Mona Kargar ${ }^{1,{ }^{*}}$, Molouk Hadjibabaie ${ }^{1}$, Kheirollah Gholami ${ }^{1}$ \\ ${ }^{1}$ Research Center for Rational Use of Drugs, Department of Clinical Pharmacy, Faculty of Pharmacy, Tehran University of Medical Sciences, Tehran, IR Iran \\ *Corresponding author: Mona Kargar, Research Center for Rational Use of Drugs, No. 92, Karimkhan Ave., Haft-e-Tir Sq., Zip Code: 1584775311, Tehran, IR Iran. Tel/Fax: +98-2188814157, \\ E-mail: mkargar@razi.tums.ac.ir.
}

Received: May 20, 2013; Accepted: Jun 01, 2013

Keywords: Dermatitis; Staphylococcus aureus; Methicillin Resistance

\section{Dear Editor,}

We read the article entitled "Colonization with Methicillin Resistant and Methicillin Sensitive Staphylococcus aureus Subtypes in Patients With Atopic Dermatitis and Its Relationship With Severity of Eczema" by Rezaei et al. (1) with great interest.

Assessment of Colonization with Staphylococcus aureus is important because of its involvement in community and healthcare associated infections (2). Since community acquired methicillin resistant Staphylococcus aureus (MRSAs) is a worldwide concern, it is really helpful for us to be aware of the pattern of colonization and antimicrobial resistance in our country especially in different patient population. However, there are some points in the article that is worth to be mentioned.

The authors evaluated the prevalence of colonization with Staphylococcus aureus in a cross sectional study of 38 patients diagnosed with atopic dermatitis (AD) presenting to the allergy clinic in a children hospital in Tehran. According to the method section of this study, there were no exclusion criteria for the patients entering this study.

However, in order to conclude that colonization with MRSAs and methicillin sensitive Staphylococcus aureus (MSSAs) in the samples obtained from patients with AD is due to the underlying disease, the high risk groups for being colonized with this organism should be excluded.

Similar studies that assessed the prevalence of Staphylococcus aureus colonization in AD patients usually excluded the patients with underlying chronic conditions like cystic fibrosis, immunodeficiency, asthma, diabetes, etc which increase the likelihood of MRSA colonization (3) as well as patients who received systemic corticosteroids, immunosuppressive drugs or systemic antibiotics in the past 4 weeks or topical antibiotics in the past 2 weeks ( 4 , 5). Otherwise, there might be probable confounding fac- tors that preclude precise conclusion.

Another point that seems to be just a written and wording problem is about obtaining the consent form from patients. Since the mean age of patients in the study was 19 months, signing the consent form by patients is undoubtedly a writing mistake.

\section{Authors' Contribution}

All the authors contributed to the development of this manuscript.

\section{Financial Disclosure}

The current article is a letter to editor and there was no source of funding or sponsor for this article.

\section{References}

1. Rezaei M, Chavoshzadeh Z, Haroni N, Armin S, Navidinia M, Mansouri M, et al. Colonization with Methicillin Resistant and Methicillin Sensitive Staphylococcus aureus Subtypes in Patients with Atopic Dermatitis and Its Relationship with Severity of Eczema. Arch Pediatr Infect Dis. 2013;1(2):53-56.

2. Miller MB, Weber DJ, Goodrich JS, Popowitch EB, Poe MD, Nyugen $\mathrm{V}$, et al. Prevalence and risk factor analysis for methicillinresistant Staphylococcus aureus nasal colonization in children attending child care centers. J Clin Microbiol. 2011;49(3):1041-7.

3. Balma-Mena A, Lara-Corrales I, Zeller J, Richardson S, McGavin MJ, Weinstein $M$, et al. Colonization with community-acquired methicillin-resistant Staphylococcus aureus in children with atopic dermatitis: a cross-sectional study. Int J Dermatol. 2011;50(6):682-8.

4. Gong JQ, Lin L, Lin T, Hao F, Zeng FQ, Bi ZG, et al. Skin colonization by Staphylococcus aureus in patients with eczema and atopic dermatitis and relevant combined topical therapy: a doubleblind multicentre randomized controlled trial. Br J Dermatol. 2006;155(4):680-7.

5. Tang CS, Wang CC, Huang CF, Chen SJ, Tseng MH, Lo WT. Antimicrobial susceptibility of Staphylococcus aureus in children with atopic dermatitis. Pediatr Int. 2011;53(3):363-7. 